\title{
Comparative effectiveness of antibiotic-impregnated shunt catheters in the treatment of adult and pediatric hydrocephalus: analysis of 12,589 consecutive cases from 287 US hospital systems
}

\author{
Scott L. Parker, MD, ${ }^{1}$ Matthew J. McGirt, MD, ${ }^{1}$ Jeffrey A. Murphy, MS, ${ }^{2}$ \\ J. Thomas Megerian, MD, PhD, ${ }^{3}$ Michael Stout, $\mathrm{BA},{ }^{2}$ and Luella Engelhart, $\mathrm{PhD}{ }^{3}$ \\ 1'Department of Neurosurgery, Vanderbilt University Medical Center, Nashville, Tennessee; '2DePuy Orthopaedics, Warsaw, \\ Indiana; and ${ }^{3}$ Codman \& Shurtleff, Inc., Raynham, Massachusetts
}

\begin{abstract}
OBJECT The real-world effectiveness of antibiotic-impregnated shunt catheters to reduce the incidence of shunt infections is still debated. The literature to date consists mostly of small, single-institution studies. The aim of this study was to assess the incidence of infection for antibiotic-impregnated catheters (AICs) versus standard shunt catheters in a large nationwide administrative database.

METHODS The authors retrospectively reviewed hospital discharge and billing records from the Premier Perspective Database from April 2003 to July 2009 to identify all adult and pediatric patients undergoing de novo ventricular shunt placement. The primary end point was the incidence of shunt infection within 1 year of implantation. Multivariate logistical regression was performed to determine factors associated with increased incidence of infection.

RESULTS A total of 10,819 adult (AIC, 963; standard catheter, 9856) and 1770 pediatric (AIC, 229; standard catheter, 1541) patients underwent ventricular shunt placement in 287 US hospitals. Overall, the incidence of infection was $3.5 \%$ in adults $(n=380)$ and $6.6 \%$ in pediatric patients $(n=116)$. AlCs were associated with significant reduction in infection for both adult $(2.2 \%$ vs $3.6 \%, p=0.02)$ and pediatric $(2.6 \%$ vs $7.1 \%, p<0.01)$ patients. AIC use was associated with reduced infection regardless of hospital size, annual shunt volume, hospital location, or patient risk factors and remained associated with a reduced infection in multivariate analysis for both adult $(p=0.02)$ and pediatric $(p=0.02)$ patients.
\end{abstract}

CONCLUSIONS The use of antibiotic-impregnated shunt catheters was associated with a reduction in shunt infections for both adult and pediatric patients. This provides further support that AICs may represent a reliable means of reducing shunt infections for both adult and pediatric patients.

http://thejns.org/doi/abs/10.3171/2014.10.JNS13395

KEY WORDS hydrocephalus; shunt; infection; antibiotic impregnated

$\mathrm{H}$ YDROCEPHALUS remains one of the most common pathologies of neurosurgery. Cerebrospinal fluid shunt systems have been the primary surgical option for the treatment of pediatric and adult hydrocephalus since their introduction in the 1950s. Although improvements in surgical technique, advances in shunt technology, and increased surgical experience have contributed to an overall decrease in shunt-related complications, ${ }^{17,20,33,34,42}$ shunt infection remains a serious complication and is associated with reduced intelligence quotient and psycho- motor retardation in children as well as meningitis, endocarditis, and prolonged hospitalization in adults. ${ }^{37,47,48}$

The incidence of CSF shunt infection generally ranges from $3 \%$ to $15 \%$, with the majority of infections occurring within the first 4 months after surgery. ${ }^{4,11-13,16,33-35}$ Infection is most often secondary to colonization of the shunt device by nonpathogenic skin flora at the time of surgery, with approximately $90 \%$ of these infections caused by Staphylococcus species. ${ }^{21}$ As early as the mid-1970s, in vitro and in vivo studies demonstrated that antibiotics incorporated

ABBREVIATIONS AIC = antibiotic-impregnated catheter; HIPAA = Health Insurance Portability and Accountability Act; ICD-9 = International Classification of Diseases, Ninth Revision.

ACCOMPANYING EDITORIAL See pp 441-442. DOI: 10.3171/2014.4.JNS14689.

SUBMITTED February 25, 2013. ACCEPTED October 7, 2014.

INCLUDE WHEN CITING Published online November 21, 2014; DOI: 10.3171/2014.10.JNS13395.

DISCLOSURE Dr. McGirt is a paid consultant for Codman \& Shurtleff, Inc. Mr. Murphy, Dr. Megerian, Mr. Stout, and Dr. Engelhart are paid employees of Johnson \& Johnson, Inc. 
into silicone rubber catheters can withstand sterilization procedures and provide local antimicrobial activity. ${ }^{67,9,2,27,30}$ Based on this research, antibiotic-impregnated shunt catheters were developed with the goal of reducing the incidence of CSF shunt infections. Antibiotic-impregnated catheters have been demonstrated to decrease colonization of shunt components by staphylocci, ${ }^{10,25,27,29,50}$ allowing for protection against early shunt infections. Since the introduction of antibiotic-impregnated shunt catheters into general clinical practice, there have been multiple clinical studies mostly reporting lower rates of infection with their use. Recent meta-analyses have also demonstrated AICs to be associated with a significant reduction in incidence of CSF shunt infection for both adult and pediatric populations. ${ }^{36,49}$

The varying conclusions of the small, single-institution studies in the literature to date underlines the importance of a large sample size study with multiple hospitals from diverse practice settings to adequately assess the potential benefit of AICs. Hence, we set out to determine the incidence of CSF shunt infection in both adult and pediatric patients undergoing ventricular shunt placement with antibiotic-impregnated versus standard shunt catheters as reported in a large nationwide administrative database.

\section{Methods \\ Data Source}

This was a retrospective longitudinal analysis of hospital discharge and billing records obtained from the Premier Perspective Database, a hospital service database that includes detailed patient-level data from inpatient hospitalizations and hospital outpatient visits. This database includes information from over 600 US hospitals with data pertaining to patient demographics (age, sex, race), hospital characteristics, principal and secondary diagnoses, payer, cost of care, medication utilization, departmental cost and charge detail, length of stay, and physician specialty. ${ }^{15}$ Participating hospitals submit data to the Premier Perspective Database on a monthly or quarterly basis. The data then undergo multiple, separate quality assurance and validation checks before being made available for research purposes. All data are de-identified in accordance with the Health Insurance Portability and Accountability Act (HIPAA).

\section{Patient Population}

All adult and pediatric patients (excluding neonates) undergoing de novo ventricular shunt placement between April 2003 and July 2009 were included into the analysis of this study. De novo shunt placement was defined as placement of a shunt in a patient who had not undergone any shunting procedure within the prior 2 years. Patients were identified by the ICD-9 (International Classification of Diseases, Ninth Revision) procedure code 02.34 (placement of a ventricular shunt to abdominal cavity and organs). The placement of an AIC was also identified based on hospital charge codes. Patients of the AIC cohort received both ventricular and distal AICs. Patients in the standard catheter cohort received no AICs of any type. The hospitalization for the initial placement of the shunt was defined as the index hospitalization. A patient's readmission can be tracked as long as the patient stays within the same hospital network.

\section{Definition of Shunt Infection}

The primary end point of this analysis was post-shunt implantation infection within 1 year of the index shunt placement. Shunt infection was defined as: 1) hospital claim with an infection diagnosis code of 996.63 (infection and inflammatory reaction due to nervous system device, implant, and graft electrodes implanted in brain) following the initial shunt insertion procedure and one or both of the following: a) shunt revision ICD-9 procedure code $(02.2$, $02.3,02.32,02.35,02.39,02.4,02.41,02.42,02.43,54.95$ ) within 1 year of the 996.63 code; b) 5 or more consecutive days of treatment with any of the following antibiotics within 7 days before or after the 996.63 infection code: ceftriaxone, ceftazidime, cefotaxime, ceftizoxime, vancomycin, gentamicin, linezolid, cefepime, meropenem, or ciprofloxacin. Time to shunt infection was measured from the date of index shunt implantation to the first occurrence of the infection-related element within the 1st year.

\section{Statistical Analysis}

To identify factors associated with shunt infection, we performed univariate analyses between preoperative variables, including patient characteristics (age, sex, race [white vs all other], number of diagnoses [a surrogate measure of patient health status severity], payment provider [Medicaid/Medicare vs private payer insurance vs other]), hospital characteristics (size [hospitals with 500 or more beds vs hospitals with less than 500 beds], region [Midwest vs Northeast vs South vs West], volume [average number of shunts placed per year], teaching status [private vs academic]), and type of catheter used (standard or antibiotic-impregnated). Kaplan-Meier survival curves were estimated to compare infection probabilities for patients treated with standard catheters and those treated with antibiotic-impregnated catheters. All variables describing preoperative patient characteristics and hospital characteristics were included in a backward selection multivariate proportional hazards model. The variable with the largest $\mathrm{p}$ value was eliminated, one variable at a time, until only variables with $\mathrm{p}$ values $\leq 0.01$ remained, creating the final reduced model. The $1 \%$ threshold was used in the multivariate proportional hazards model reduction because the traditional cutoff $(5 \%)$ is not useful when reducing large (> 50) sample sizes. ${ }^{38}$ For univariate analysis, $p$ values $<0.05$ were considered significant. Analyses were conducted separately for the adult and pediatric populations (age 17 years and younger). The pediatric population had no age variable since it was unavailable for children under age 15 years due to HIPAA compliance.

All analyses were performed using SAS v9.3 (SAS Institute, Inc). Summary data were presented as means \pm standard deviations for parametric data. Percentages were compared via the chi-square test for intergroup comparison, and the Student t-test was used for parametric data, unless there was an indication that the variances were unequal (using the folded F-test), whereupon the Satterthwaite t-test was used instead.

\section{Results}

\section{Treatment Population}

A total of 12,589 consecutive adult and pediatric pa- 
tients from 287 hospitals undergoing de novo ventricular shunt placement were identified during the reviewed period. A total of $10,819(85.9 \%)$ shunts were placed in the adult population and $1770(14.1 \%)$ were placed in pediatric $(<18$ years old, not including neonates) patients. The patients' mean age $( \pm$ SD) at the time of shunt placement was $62.7 \pm 17.7$ years in the adult population. Age was not available in the pediatric cohort due to HIPAA compliance. The adult population included 5468 (50.5\%) males and $5351(49.5 \%)$ females, while the pediatric population included $958(54.1 \%)$ males and $812(45.9 \%)$ females.

In the adult population, $963(8.9 \%)$ patients received antibiotic-impregnated shunt catheters and 9856 (91.1\%) received standard shunt catheters. In the pediatric population, 229 (12.9\%) patients underwent placement of AICs and $1541(87.1 \%)$ underwent placement of standard shunt catheters. Baseline patient demographics and hospital characteristics for the 2 cohorts are summarized in Table 1 .

\section{Shunt Infections}

In the adult population, a total of 380 patients (3.5\%) experienced a shunt infection within 1 year of the index shunt placement. The overall mean time to shunt infection for adults was $10.4 \pm 11.7$ weeks. The use of AICs was associated with a reduced incidence of shunt infection (Fig. 1). Twenty-one (2.2\%) of the patients with AICs versus $359(3.6 \%)$ of the patients with standard catheters experienced a shunt infection $(p=0.02)$. There was no significant difference in time to shunt infection between the
AIC and standard catheter cohorts $(13.2 \pm 14.4$ vs $10.2 \pm$ 11.6 weeks, $\mathrm{p}=0.26$ ).

In the pediatric population, a total of $116(6.6 \%)$ patients experienced a shunt infection within 1 year of the index shunt placement. The overall mean time to shunt infection for pediatric patients was $11.7 \pm 13$. 6 weeks. The use of AICs was associated with a reduced incidence of shunt infection (Fig. 2). Six (2.6\%) of the patients in the AIC cohort versus $110(7.1 \%)$ of the patients in the standard catheter cohort experienced a shunt infection $(\mathrm{p}<$ 0.01 ). There was no significant difference in time to shunt infection between the AIC and standard catheter cohorts $(16.9 \pm 17.3$ vs $11.4 \pm 13.4$ days, $p=0.34)$.

In stepwise multivariate analysis, variables that remained significantly associated with likelihood of shunt infection in the adult population were increased age (HR $0.983, \mathrm{p}<0.0001$ ) and increased number of diagnoses (HR 1.024, $\mathrm{p}<0.0001)$. Use of an AIC (HR 0.601, $\mathrm{p}=0.023$ ) was not below the $1 \%$ p-value threshold but approached this significance level. Medicaid payer status (HR 1.895, $\mathrm{p}=0.002$ ) was the only variable that remained significantly associated with likelihood of shunt infection in the pediatric population; however, use of an AIC (HR 0.371, $\mathrm{p}=0.018$ ) was not below the $1 \% \mathrm{p}$-value threshold but approached this significance level (Table 2).

\section{Discussion}

In the analysis of this large nationwide database encompassing 287 hospitals and 12,589 consecutive patients

TABLE 1. Univariate comparisons of patient and hospital characteristics for adult and pediatric patients receiving antibiotic-impregnated and standard shunt catheters*

\begin{tabular}{|c|c|c|c|}
\hline Cohort \& Variable & $\mathrm{AIC}$ & Standard Catheter & $\mathrm{p}$ Value \\
\hline \multicolumn{4}{|l|}{ Adult cohort } \\
\hline Mean age (yrs) & $64.4 \pm 18.0$ & $62.5 \pm 17.7$ & $<0.01 \dagger$ \\
\hline Male sex (\%) & 50.2 & 50.6 & $0.80 \ddagger$ \\
\hline White (\%) & 77.1 & 68.8 & $<0.01 \ddagger$ \\
\hline Mean no. of diagnoses & $12.6 \pm 8.2$ & $11.6 \pm 7.8$ & $<0.01 \S$ \\
\hline Private payer (\%) & 25.3 & 29.9 & $0.01 \ddagger$ \\
\hline Hospital w/ 500+ beds (\%) & 68.5 & 52.8 & $<0.01 \ddagger$ \\
\hline Academic hospital (\%) & 39.5 & 58.0 & $<0.01 \ddagger$ \\
\hline Region: South (\%) & 66.7 & 45.9 & $<0.01 \ddagger$ \\
\hline Mean hospital shunt volumeף & $24.0 \pm 20.3$ & $36.6 \pm 45.9$ & $<0.01 \S$ \\
\hline \multicolumn{4}{|l|}{ Pediatric cohort } \\
\hline Male (\%) & 50.2 & 54.7 & $0.20 \ddagger$ \\
\hline White (\%) & 59.8 & 54.3 & $0.11 \ddagger$ \\
\hline Mean no. of diagnoses & $9.1 \pm 8.5$ & $8.1 \pm 7.8$ & $0.06 \dagger$ \\
\hline Private payer (\%) & 41.5 & 40.0 & $0.16 \ddagger$ \\
\hline Hospital w/ 500+ beds (\%) & 38.0 & 67.4 & $<0.01 \ddagger$ \\
\hline Academic hospital (\%) & 75.6 & 73.2 & $0.45 \ddagger$ \\
\hline Region: South (\%) & 76.0 & 66.3 & $<0.01 \ddagger$ \\
\hline Mean hospital shunt volumeף & $29.6 \pm 13.5$ & $44.3 \pm 32.2$ & $<0.01 \S$ \\
\hline $\begin{array}{l}\text { * Mean values are presented with SDs. } \\
\text { † Student t-test. } \\
\ddagger \text { Chi-square test. } \\
\text { § Satterthwaite t-test. } \\
\text { † Average number of shunts placed per year. }\end{array}$ & & & \\
\hline
\end{tabular}




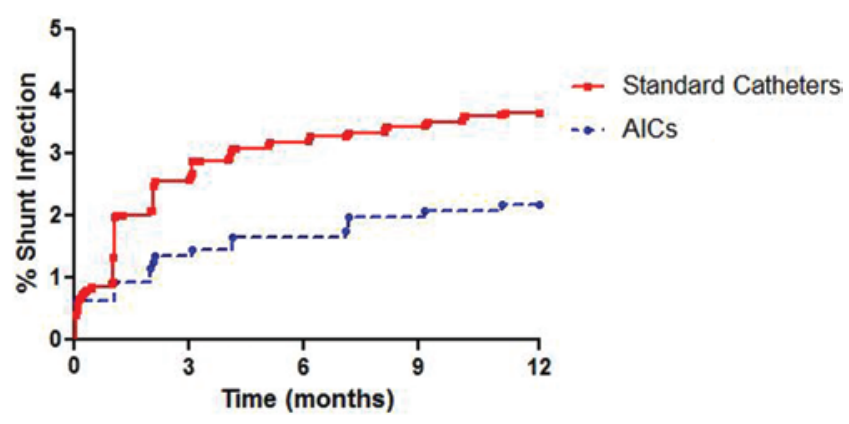

FIG. 1. Kaplan-Meier curve demonstrating shunt infection as a function of time after shunt insertion in adult patients receiving antibioticimpregnated and standard shunt catheters. By 12 months after shunt placement, only $21(2.2 \%)$ of the patients with antibiotic-impregnated catheters (AICs) experienced a shunt infection compared with 359 $(3.6 \%)$ of the patients with standard catheters $(p=0.02)$. Figure is available in color online only.

undergoing placement of a ventricular shunt, antibioticimpregnated catheters (AICs) were associated with a reduced incidence of shunt infection for both adult and pediatric patient populations. The use of AICs was associated with $1.4 \%(\mathrm{p}=0.02)$ and $4.5 \%(\mathrm{p}<0.01)$ infection reduction in adult and pediatric populations, respectively. This infection reduction remained statistically significant in multivariate analyses. The mean time to shunt infection was $10.4 \pm 11.7$ and $11.7 \pm 13.6$ weeks in the adult and pediatric populations, respectively. These findings are based on the largest and most diverse patient population studied to date in the area of ventricular shunt systems, supporting findings from previous studies with smaller patient populations from single institutions. . $20,22,28,37,44^{2}$

The findings of the current study are consistent with previous systematic reviews and meta-analyses of the literature, each of which found antibiotic-impregnated shunt catheters to be associated with a reduced incidence of CSF infection. ${ }^{36,49}$ The systematic literature review by Parker et al. demonstrated AICs to be associated with a significant infection reduction overall (3.3\% vs $7.2 \%)$, in adultspecific cohorts $(0.9 \%$ vs $5.8 \%)$, and in pediatric-specific cohorts $(5.0 \%$ vs $11.2 \%) .{ }^{36}$ Similarly, the meta-analysis performed by Thomas et al. concluded that AICs may be an effective means of reducing the incidence of shunt and external ventricular drain infections. ${ }^{49}$

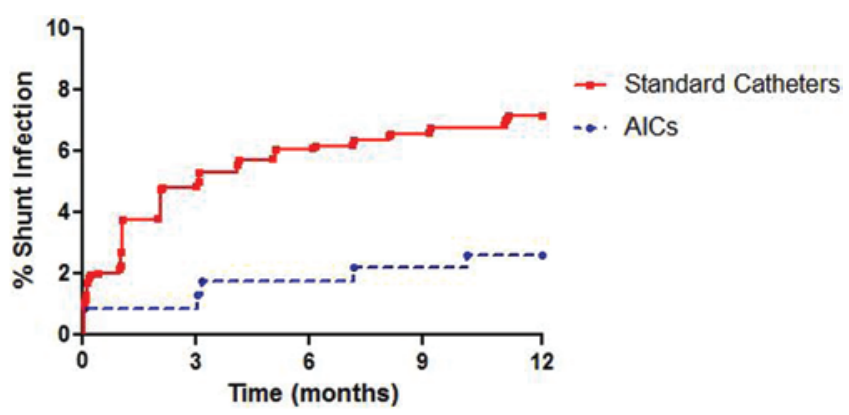

FIG. 2. Kaplan-Meier curve demonstrating shunt infection as a function of time after shunt insertion in pediatric patients receiving antibioticimpregnated and standard shunt catheters. By 12 months after shunt placement, only $6(2.6 \%)$ of the patients with AICs experienced a shunt infection compared with $110(7.1 \%)$ of the patients with standard catheters $(p<0.01)$. Figure is available in color online only.
TABLE 2. Variables remaining significantly associated with likelihood of shunt infection in multivariate analysis

\begin{tabular}{llc}
\hline Cohort \& Covariate & HR & p Value \\
\hline Adult cohort & & \\
\hline Increased age & 0.983 & $<0.0001$ \\
\hline Increased no. of diagnoses & 1.024 & $<0.0001$ \\
\hline AIC & 0.601 & 0.023 \\
\hline Pediatric cohort & & \\
\hline Medicaid/Medicare payer ${ }^{*}$ & 1.895 & 0.002 \\
\hline AIC & 0.371 & 0.018 \\
\hline
\end{tabular}

* The "payer" variable had 3 categories: 1) Medicaid/Medicare, 2) private insurance, and 3 ) other. The private insurance category was the reference category.

Ventricular shunts provide a reliable means of treatment for hydrocephalus in both adult and pediatric patients; however, shunt infection remains a relatively common complication, occurring in $5 \%-10 \%$ of patients. ${ }^{36,49}$ This represents a 3- to 5-fold increase in infection rate compared with other neurosurgical procedures. ${ }^{24}$ Most often, infection results from colonization of the shunt system by normally nonpathogenic skin flora at the time of surgery. Properties of the foreign body itself may contribute to this increased risk of infection, and most infections are clinically apparent within the first 6 months following surgery. Previous studies have attempted to identify risk factors associated with CSF shunt infection. Accepted independent risk factors include but are not limited to prematurity, age, etiology of hydrocephalus, and previous shunt failure. . $^{17,19,31,32,41,43,45}$ Despite significant improvement in surgical technique, perioperative antibiotic therapy, adherence to sterilization techniques, and appreciation of the aforementioned risk factors, low infection rates are not consistently achieved. ${ }^{17}$ Antibiotic-impregnated shunt catheters have previously been demonstrated to specifically reduce the incidence of infection in patients at highest risk for infection. ${ }^{37}$

The silicon matrix of antibiotic-impregnated shunt catheters is impregnated with rifampicin $(0.54 \%)$ and clindamycin $(0.15 \%)$ to target gram-positive bacteria, especially Staphylococcus species, which have been shown to cause approximately two-thirds of all shunt infections. ${ }^{14,24}$ These pathogens produce a glycoprotein biofilm that facilitates adherence to the catheter surface and impedes the normal immunological response. ${ }^{26,40}$ Antibiotic-impregnated shunt catheters were developed with the intent to prevent this type of colonization by Staphylococcus species on the catheter surface. ${ }^{8,29,30}$ While the dual drug formulation (rifampicin and clindamycin) was designed to reduce the occurrence of resistant mutations, some concerns have been raised that AICs may select for resistant and more virulent microorganisms. However, a previous study has demonstrated a comparable incidence of oxacillin-resistant Staphylococcus aureus between AIC and standard catheter cohorts. ${ }^{37}$ Furthermore, a previous systematic review of the literature evaluating infection in AIC versus standard catheter cohorts demonstrated a similar overall incidence of causative gram-negative infectious organisms in each cohort, further demonstrating that AICs likely do not predispose to infections by pathogens not covered by the locally released 
antibiotics. ${ }^{36}$ Furthermore, long-term implantation of AICs has not been shown to be associated with additional risk of seizures or drug resistance, as is seen with the long-term use of systemic antibiotics. ${ }^{1,46}$

Analyses of large administrative databases such as this one can provide valuable information but have inherent limitations with regard to determination of causality. As with all retrospective analyses, it was not possible to completely control for all patient and surgeon characteristics that may affect the selection of treatment or the risk of infection. It is possible that confounders not measured may have resulted in a bias of the data, and this should be kept in mind when interpreting our results. The observational design and potential unobserved confounders provide a weaker framework for causal inference of exposure-disease associations than randomized controlled studies. In a study of this size, small differences can still be statistically significant due to the overpowered nature of the study. Nonetheless, we believe that the $1.4 \%(\mathrm{p}=0.023)$ and $4.5 \%(\mathrm{p}=0.018)$ infection reduction and associated $\mathrm{p}$ values in multivariate analysis for the adult and pediatric populations, respectively, represent both statistically and clinically significant differences.

Other limitations specific to administrative claims databases result from the fact that data are not specifically collected for research purposes. As a result, diagnostic information and resource use can be missing or incorrectly entered, each of which limits the inferences that can be made from the data. In the current study, patients could be accurately tracked longitudinally only if they received care at a hospital within the network of the Premier Perspective Database. Thus it is possible that some infections may not have been accounted for in this analysis. Additionally, our definition of infection, which included overlying criteria, was specifically chosen to reduce the incidence of falsepositive infections; nevertheless, it remains possible that a small minority of the infections counted in this study may not be true infections.

While the types of missing data or coding errors discussed above are certainly possible, the number of errors would likely be small and distributed in equal proportions to the two treatment groups of interest (AICs vs standard catheters). As such, these errors would be expected to impact the two treatment groups equally and have minimal effect on their comparative differences.

By combining a consecutive series of adult and pediatric patients from multiple institutions, practice settings, and patient populations, the current study provides the most comprehensive assessment of antibiotic-impregnated versus standard shunt catheters to date. Independent of all other patient and hospital variables, the use of AICs was associated with a significant reduction in shunt infection for both adult and pediatric patients undergoing de novo ventricular shunt placement. These findings add to the growing evidence that AICs may decrease the incidence of shunt infection in the treatment of both adult and pediatric hydrocephalus. Furthermore, it has been previously demonstrated that shunt infections are associated with a significant financial impact, as the average hospital cost for the treatment of a shunt infection is approximately $\$ 50,000$, representing the most costly implant-related infection in the US. ${ }^{5,18,23,39}$ While not the primary objective of the current study, the significant reduction in infection incidence associated with AICs could dramatically reduce the health care costs associated with catheter-related CSF infections.

\section{Conclusions}

The use of antibiotic-impregnated shunt catheters was associated with a reduction in shunt infections for both adult and pediatric patients. This provides further support that AICs may represent a reliable means of reducing shunt infections for both adult and pediatric patients.

\section{References}

1. Abed WT, Alavijeh MS, Bayston R, Shorvon SD, Patsalos PN: An evaluation of the epileptogenic properties of a rifampicin/ clindamycin-impregnated shunt catheter. Br J Neurosurg 8:725-730, 1994

2. Albanese A, De Bonis P, Sabatino G, Capone G, Marchese E, Vignati A, et al: Antibiotic-impregnated ventriculo-peritoneal shunts in patients at high risk of infection. Acta Neurochir (Wien) 151:1259-1263, 2009

3. Ammirati M, Raimondi AJ: Cerebrospinal fluid shunt infections in children. A study on the relationship between the etiology of hydrocephalus, age at the time of shunt placement, and infection rate. Childs Nerv Syst 3:106-109, 1987

4. Aryan HE, Meltzer HS, Park MS, Bennett RL, Jandial R, Levy ML: Initial experience with antibiotic-impregnated silicone catheters for shunting of cerebrospinal fluid in children. Childs Nerv Syst 21:56-61, 2005

5. Attenello FJ, Garces-Ambrossi GL, Zaidi HA, Sciubba DM, Jallo GI: Hospital costs associated with shunt infections in patients receiving antibiotic-impregnated shunt catheters versus standard shunt catheters. Neurosurgery 66:284-289, 2010

6. Bayston R: The antibacterial effects of impregnated silastic and its possible applications in surgery. J Pediatr Surg 12:55-61, 1977

7. Bayston R: Preliminary studies on the impregnation of silastic elastomers with antimicrobial substances. Dev Med Child Neurol Suppl 18:50-54, 1976

8. Bayston R, Ashraf W, Bhundia C: Mode of action of an antimicrobial biomaterial for use in hydrocephalus shunts. J Antimicrob Chemother 53:778-782, 2004

9. Bayston R, Grove N, Siegel J, Lawellin D, Barsham S: Prevention of hydrocephalus shunt catheter colonisation in vitro by impregnation with antimicrobials. J Neurol Neurosurg Psychiatry 52:605-609, 1989

10. Bayston R, Lambert E: Duration of protective activity of cerebrospinal fluid shunt catheters impregnated with antimicrobial agents to prevent bacterial catheter-related infection. J Neurosurg 87:247-251, 1997

11. Bayston R, Lari J: A study of the sources of infection in colonised shunts. Dev Med Child Neurol 16 (6 Suppl 32):16-22, 1974

12. Blount JP, Campbell JA, Haines SJ: Complications in ventricular cerebrospinal fluid shunting. Neurosurg Clin N Am 4:633-656, 1993

13. Borgbjerg BM, Gjerris F, Albeck MJ, Børgesen SE: Risk of infection after cerebrospinal fluid shunt: an analysis of 884 first-time shunts. Acta Neurochir (Wien) 136:1-7, 1995

14. Borges LF: Cerebrospinal fluid shunts interfere with host defenses. Neurosurgery 10:55-60, 1982

15. Burke TA, Wisniewski T, Ernst FR: Resource utilization and costs associated with chemotherapy-induced nausea and vomiting (CINV) following highly or moderately emetogenic chemotherapy administered in the US outpatient hospital setting. Support Care Cancer 19:131-140, 2011

16. Chapman PH, Borges LF: Shunt infections: prevention and treatment. Clin Neurosurg 32:652-664, 1985 
17. Choux M, Genitori L, Lang D, Lena G: Shunt implantation: reducing the incidence of shunt infection. J Neurosurg 77:875-880, 1992

18. Darouiche RO: Treatment of infections associated with surgical implants. N Engl J Med 350:1422-1429, 2004

19. Erşahin Y, Mutluer S, Güzelbă̆ E: Cerebrospinal fluid shunt infections. J Neurosurg Sci 38:161-165, 1994

20. Eymann R, Chehab S, Strowitzki M, Steudel WI, Kiefer M: Clinical and economic consequences of antibiotic-impregnated cerebrospinal fluid shunt catheters. J Neurosurg Pediatr 1:444-450, 2008

21. Fan-Havard P, Nahata MC: Treatment and prevention of infections of cerebrospinal fluid shunts. Clin Pharm 6:866-880, 1987

22. Farber SH, Parker SL, Adogwa O, McGirt MJ, Rigamonti D: Effect of antibiotic-impregnated shunts on infection rate in adult hydrocephalus: a single institution's experience. Neurosurgery 69:625-629, 2011

23. Farber SH, Parker SL, Adogwa O, Rigamonti D, McGirt MJ: Cost analysis of antibiotic-impregnated catheters in the treatment of hydrocephalus in adult patients. World Neurosurg 74:528-531, 2010

24. Gardner P, Leipzig T, Phillips P: Infections of central nervous system shunts. Med Clin North Am 69:297-314, 1985

25. Govender ST, Nathoo N, van Dellen JR: Evaluation of an antibiotic-impregnated shunt system for the treatment of hydrocephalus. J Neurosurg 99:831-839, 2003

26. Gray ED, Peters G, Verstegen M, Regelmann WE: Effect of extracellular slime substance from Staphylococcus epidermidis on the human cellular immune response. Lancet 1:365-367, 1984

27. Hampl J, Schierholz J, Jansen B, Aschoff A: In vitro and in vivo efficacy of a rifampin-loaded silicone catheter for the prevention of CSF shunt infections. Acta Neurochir (Wien) 133:147-152, 1995

28. Hayhurst C, Cooke R, Williams D, Kandasamy J, O'Brien DF, Mallucci CL: The impact of antibiotic-impregnated catheters on shunt infection in children and neonates. Childs Nerv Syst 24:557-562, 2008

29. Kockro RA, Hampl JA, Jansen B, Peters G, Scheihing M, Giacomelli R, et al: Use of scanning electron microscopy to investigate the prophylactic efficacy of rifampin-impregnated CSF shunt catheters. J Med Microbiol 49:441-450, 2000

30. Kohnen W, Schäper J, Klein O, Tieke B, Jansen B: A silicone ventricular catheter coated with a combination of rifampin and trimethoprim for the prevention of catheter-related infections. Zentralbl Bakteriol 287:147-156, 1998

31. Kulkarni AV, Drake JM, Lamberti-Pasculli M: Cerebrospinal fluid shunt infection: a prospective study of risk factors. J Neurosurg 94:195-201, 2001

32. Mancao M, Miller C, Cochrane B, Hoff C, Sauter K, Weber E Cerebrospinal fluid shunt infections in infants and children in Mobile, Alabama. Acta Paediatr 87:667-670, 1998

33. McGirt MJ, Woodworth G, Coon AL, Thomas G, Williams MA, Rigamonti D: Diagnosis, treatment, and analysis of longterm outcomes in idiopathic normal-pressure hydrocephalus. Neurosurgery 57:699-705, 2005

34. McGirt MJ, Woodworth G, Thomas G, Miller N, Williams M, Rigamonti D: Cerebrospinal fluid shunt placement for pseudotumor cerebri-associated intractable headache: predictors of treatment response and an analysis of long-term outcomes. J Neurosurg 101:627-632, 2004

35. Odio C, McCracken GH Jr, Nelson JD: CSF shunt infections in pediatrics. A seven-year experience. Am J Dis Child 138:1103-1108, 1984

36. Parker SL, Anderson WN, Lilienfeld S, Megerian JT, McGirt MJ: Cerebrospinal shunt infection in patients receiving antibiotic-impregnated versus standard shunts. A review. J Neurosurg Pediatr 8:259-265, 2011
37. Parker SL, Attenello FJ, Sciubba DM, Garces-Ambrossi GL, Ahn E, Weingart J, et al: Comparison of shunt infection incidence in high-risk subgroups receiving antibiotic-impregnated versus standard shunts. Childs Nerv Syst 25:77-83, 2009

38. Patetta M: Survival Analysis Using the Proportional Hazards Model: Course Notes. Cary, NC: SAS Institute, 2001, p 151

39. Patwardhan RV, Nanda A: Implanted ventricular shunts in the United States: the billion-dollar-a-year cost of hydrocephalus treatment. Neurosurgery 56:139-145, 2005

40. Peters G, Locci R, Pulverer G: Adherence and growth of coagulase-negative staphylococci on surfaces of intravenous catheters. J Infect Dis 146:479-482, 1982

41. Pople IK, Bayston R, Hayward RD: Infection of cerebrospinal fluid shunts in infants: a study of etiological factors. J Neurosurg 77:29-36, 1992

42. Puca A, Anile C, Maira G, Rossi G: Cerebrospinal fluid shunting for hydrocephalus in the adult: factors related to shunt revision. Neurosurgery 29:822-826, 1991

43. Renier D, Lacombe J, Pierre-Kahn A, Sainte-Rose C, Hirsch JF: Factors causing acute shunt infection. Computer analysis of 1174 operations. J Neurosurg 61:1072-1078, 1984

44. Richards HK, Seeley HM, Pickard JD: Efficacy of antibioticimpregnated shunt catheters in reducing shunt infection: data from the United Kingdom Shunt Registry. Clinical article. J Neurosurg Pediatr 4:389-393, 2009

45. Rogers EA, Kimia A, Madsen JR, Nigrovic LE, Neuman MI: Predictors of ventricular shunt infection among children presenting to a pediatric emergency department. Pediatr Emerg Care 28:405-409, 2012

46. Sciubba DM, McGirt MJ, Woodworth GF, Carson B, Jallo GI: Prolonged exposure to antibiotic-impregnated shunt catheters does not increase incidence of late shunt infections. Childs Nerv Syst 23:867-871, 2007

47. Sciubba DM, Noggle JC, Carson BS, Jallo GI: Antibioticimpregnated shunt catheters for the treatment of infantile hydrocephalus. Pediatr Neurosurg 44:91-96, 2008

48. Sciubba DM, Stuart RM, McGirt MJ, Woodworth GF, Samdani A, Carson B, et al: Effect of antibiotic-impregnated shunt catheters in decreasing the incidence of shunt infection in the treatment of hydrocephalus. J Neurosurg 103 (2 Suppl):131-136, 2005

49. Thomas R, Lee S, Patole S, Rao S: Antibiotic-impregnated catheters for the prevention of CSF shunt infections: a systematic review and meta-analysis. Br J Neurosurg 26:175-184, 2012

50. Walters BC, Hoffman HJ, Hendrick EB, Humphreys RP: Cerebrospinal fluid shunt infection. Influences on initial management and subsequent outcome. J Neurosurg 60:10141021,1984

\section{Author Contributions}

Conception and design: Engelhart, Parker, McGirt. Acquisition of data: Murphy, Megerian, Stout. Drafting the article: Parker. Critically revising the article: all authors. Reviewed submitted version of manuscript: all authors. Statistical analysis: Murphy, Stout. Administrative/technical/material support: Engelhart, Megerian.

\section{Supplemental Information \\ Current Affiliation \\ Dr. McGirt: Carolina Neurosurgery \& Spine Associates, Charlotte, NC}

\section{Correspondence}

J. Thomas Megerian, 325 Paramount Dr., Raynham, MA 02767. email: jmegeri1@its.jnj.com. 